\title{
Una aproximación a la brecha digital de las personas con discapacidad en los espacios educativos del noroeste $\operatorname{argentino~}^{1}$
}

\section{Mauro Alejandro Soto 2}

Recibido: 04/09/2019; Aceptado: 12/11/2019

Cómo citar: Soto, M. A. (2020) Una aproximación a la brecha digital de las personas con discapacidad en los espacios educativos del noroeste argentino. Revista Hipertextos, 8 (13), pp. 115149. DOI: https://doi.org/10.24215/23143924e012

\section{Resumen}

El acceso a las tecnologías digitales es un derecho humano ampliamente garantizado para las personas con discapacidad, en tanto estas aportan a la inclusión social, a la autonomía y vida independiente. Asimismo, las mismas, usadas y desarrolladas bajo los principios de accesibilidad y criterios de diseño universal, pueden contribuir significativamente a los procesos de educación inclusiva del colectivo con discapacidad.

Partiendo de este reconocimiento, se exponen los primeros avances de una investigación que indaga en la brecha digital de las personas con discapacidad en los espacios educativos del noroeste argentino. Por medio de un recorrido bibliográfico se explicitarán los principios epistemológicos que la estructuran, los conceptos teóricos que delimitan el objeto de estudio y los aportes de otras investigaciones conexas que brindan información para su contextualización.

Palabras clave: tecnologías digitales, modelo social, discapacidad, enfoque socio-técnico, educación inclusiva.

1 Una versión preliminar de este trabajo fue presentada como ponencia en las Jornadas de Sociología, organizadas por la Facultad de Cs. Sociales (UBA) en 2019.

2 Universidad Nacional de Salta (UNSa), Consejo Nacional de investigaciones Científicas y Técnicas (Conicet); Licenciado en Ciencias de la Comunicación, Especialista en Educación y Nuevas Tecnologías, doctorando en Ciencias Sociales Universidad de Buenos Aires. Contacto: maurosotoal@gmail.com 


\begin{abstract}
Access to digital technologies is a widely recognized human right for people with disabilities, as they contribute to social inclusion, autonomy and independent living. Furthermore, when digital technologies are used and developed under the principles of accessibility and universal design criteria, they can contribute significantly to the processes of inclusive education for disabled people. Departing from this recognition, it is exposed the first advances of a research that investigates the digital gap of the people with disabilities in the educational spaces of the Argentine Northwest. By means of a bibliographic journey, the epistemological principles that structure this research, the theoretical concepts that delimit the object of study and the contributions of other related researches that provide information for its contextualization will be explained.
\end{abstract}

Keywords: digital technologies, social model, disability, socio-technical approach, inclusive education.

\title{
Resumo
}

$\mathrm{O}$ acesso às tecnologias digitais é um direito humano vastamente garantido para as pessoas com deficiência, enquanto contribuem a sua inclusão social, autonomia e vida independente. Da mesma forma, usadas e desenvolvidas sob os princípios de acessibilidade e critérios do desenho universal, podem contribuir significativamente aos processos de educação inclusiva do grupo com deficiência. A partir desse reconhecimento, são expostos os primeiros avanços de uma investigação que pesquisa a lacuna digital entre as pessoas com deficiência nos espaços educacionais do noroeste da Argentina. Através de uma revisão da bibliografia, serão explicados os princípios epistemológicos que a estruturam, os conceitos teóricos que delimitam o objeto de estudo e as contribuições de outras pesquisas relacionadas que fornecem informações para sua contextualização.

Palavras-chave: tecnologias digitais, modelo social, deficiência, abordagem sociotécnica, educação inclusiva. 


\section{Introducción}

Diferentes investigaciones dan cuenta de los aportes significativos de las Tecnologías digitales (TD) para la inclusión y participación de las Personas con Discapacidad (PCD) en un amplio abanico de prácticas sociales (García Bilbao y Rodríguez Porrero, 2000; Labrada Martínez, 2011; Raja, 2016). En el caso particular de las educativas, estas tecnologías, construidas y empleadas bajo principios de accesibilidad y criterios de diseño universal, pueden favorecer significativamente a los procesos de educación inclusiva del colectivo con discapacidad al posibilitar superar barreras físicas, temporales, cognitivas y sensoriales en diferentes discapacidades (Luque Parra y Rodríguez Infante, 2009; Cabezas, 2016; Sánchez Montoya, 2016; Silva Sández y Rodríguez Miranda, 2018). Una educación que resulta relevante para las PCD, debido a que se constituye en un derecho humano fundamental que brinda un capital social necesario para acceder a otros derechos como la cultura y el trabajo (OMS, 2011: 11) y que es uno de los derechos más difíciles de concretar y garantizar por parte de los Estados (Palacios, 2017).

Pese a sus aportes, y más allá de una amplia legislación que lo garantiza (ONU, 2006), las PCD no tienen un pleno acceso a las TD. Esto debido a una forma particular de brecha digital, compleja y dinámica, producida por la lógica de producción en red del capitalismo cognitivo o informacional (Castells, 2009) que genera condiciones de desigualdad en el acceso a estas tecnologías entre regiones, países, y grupos sociales y culturales; y por otros que constituyen la discapacidad como la ausencia de hardware y software construido bajo los principios de accesibilidad y diseño universal (Ferreira y Díaz Velásquez, 2009) y una marcada exclusión educativa, laboral y cultural.

Dado el papel de la brecha digital en la exclusión de las personas con discapacidad y como barrera a la participación social, en el presente trabajo exponemos los avances de una investigación que busca contribuir al conocimiento del estado de las condiciones de accesibilidad de las Personas con Discapacidad (PCD) a las Tecnologías Digitales (TD) en la región del Noroeste Argentino (NOA) desde un enfoque socio-técnico; haciendo foco en las barreras y facilitadores que amplían o reducen la brecha digital que experimenta el colectivo en los espacios educativos del nivel secundario de la región.

En este sentido, y por medio de una reconstrucción bibliográfica, el presente artículo se propone brindar un acercamiento a los principios epistemológicos y 
los conceptos teóricos que la estructuran; poniéndolos en diálogo con investigaciones que convergen o circundan con nuestros objetivos en el espacio geográfico e institucional que nos atañe. De esta manera, no solo buscaremos por esta vía reconstruir nuestro objeto de estudio, sino también contextualizarlo en el NOA.

A modo de organización, delimitamos tres apartados más una conclusión. En el primero de ellos, indagaremos en algunas condiciones particulares que produce el capitalismo cognitivo; fundamentalmente, en el complejo y dinámico fenómeno de la brecha digital, y en cómo esta construye en sus extremos facilitadores o barreras para la inclusión social de las PCD.

En segundo lugar, indagaremos en la discapacidad, el acceso a las TD y a la educación desde la perspectiva del modelo social de la discapacidad y los Derechos Humanos.

En la tercera parte, nos acercaremos a la brecha digital en los espacios educativos para las PCD, buscando conocer cómo las TD pueden contribuir a los procesos de educación inclusiva, u obstaculizarlos si se emplea a estas bajo criterios de normalidad.

Finalmente, ofreceremos un resumen de los principales hallazgos de este recorrido.

\section{Sobre el capitalismo cognitivo}

Como primer paso, resulta conveniente aproximarnos a algunas características del capitalismo cognitivo, y fundamentalmente, en cómo su modo de producción particular se relaciona con una estructura ambigua basada en dinámicas de desarrollo y desigualdad a nivel global.

Al respecto, este sistema socio-económico basa su producción, a diferencia de sus predecesores, en el uso intensivo del conocimiento como insumo principal o materia prima. No se trata aquí de cualquier conocimiento, pues éste, en su sentido más amplio, ha tenido un papel relevante en toda forma de producción a lo largo de la historia de la humanidad; y que podremos distinguir a partir de una breve taxonomía basada en las formas que sirven de soporte a 
dichos $\operatorname{conocimientos}^{3}$ : conocimiento biológico, subjetivo, intersubjetivo y objetivo.

Es en este último donde profundizaremos, en tanto se constituye en el tipo de conocimiento que emplea de forma intensiva el capitalismo cognitivo. Así, el conocimiento objetivo se divide en objetivado y codificado. El primero hace referencia a que el mismo se cristaliza en la forma del objeto soporte. Del amplio conjunto de conocimientos objetivados instrumentales (herramientas o máquinas) desarrollados por la humanidad, nos interesa destacar para este trabajo el caso de las TD. Estas se cristalizan en artefactos (máquinas) capaces de almacenar, procesar, reproducir, transmitir y convertir información digital. Dichas tecnologías, que incluyen al hardware y al software, poseen propiedades económicas específicas que la diferencian de toda otra tecnología (un carácter virtuoso y cíclico de la innovación del sector). Asimismo, tienen la particularidad de que pueden integrar en los mismos artefactos todas las funciones de este tipo de tecnologías (almacenar, procesar, etc.), debido a que la información digital funciona como una suerte de equivalente general (Zukerfeld, 2015).

Respecto al conocimiento objetivo codificado, el mismo se define por resguardarse en el contenido simbólico del objeto soporte y gran parte de éste puede ser pensado como información (texto, imágenes, audio, entre otros). Interesa aquí destacar a la información digital, como un conocimiento objetivo codificado binariamente en señales eléctricas de encendido-apagado capaz de ser clonado a un valor ínfimo. Esto implica que los conocimientos que hayan sido traducidos a él, podrán replicarse de forma idéntica, casi sin costo alguno (Zukerfeld, 2008: 56).

Lo destacable en este estadio de la historia es que las transformaciones socio-productivas tienen a las TD y a la información digital como herramientas e insumos fundamentales, respectivamente, para la producción de un tipo específico de mercancía: los bienes informacionales. Esto implica que la generación o acceso a la información digital resulta estratégica para la producción económica, por lo que las mayores inversiones en capital y trabajo se dan en estas áreas. A su vez, esto coloca al costo de la información digital

\footnotetext{
${ }^{3}$ Este es un resumen basado en un esquema sobre los tipos de conocimientos desarrollado en el trabajo de Mariano Zukerfeld "Capitalismo cognitivo, trabajo informacional y un poco de música" (2008). Para profundizar recomendamos leer el "Capítulo VI", del Volumen I de la Tesis de doctorado del citado autor (Zukerfeld, 2012).
} 
como significativamente superior a la materia o a la energía empleadas en los procesos de producción. Dicho todo esto, podemos llegar a una definición más precisa de este sistema socio-productivo:

Llamamos capitalismo cognitivo a la etapa del modo de producción capitalista signada por la contradicción entre relaciones sociales de producción orientadas a realizar los (...) bienes informacionales como mercancías, y el grado de desarrollo de las fuerzas productivas asociado a la ontología replicable de la información digital, que amenaza el estatus mercantil de esos bienes (Zukerfeld, 2008: 57).

\subsection{La brecha digital: otra cara de la desigualdad social}

Ahora bien, la distribución y acceso a las TD e información digital no es homogénea o equitativa a nivel global. Esto se debe a la lógica de la estructura red de producción, que conecta solo lo que vale desde el punto de vista de lo que funciona y produce en el sistema (Castells, 2009). De esta manera, esos procesos de conexión asimétricos van generando un incremento de la desigualdad entre regiones, entre los países, entre las personas dentro de las sociedades; hecho que se advierte en el fenómeno complejo y dinámico de la brecha digital.

Esta última se la define como la diferencia existente entre grupos sociales que, por un lado, poseen acceso a las TD, que las emplean en la vida cotidiana, saben utilizarlas, acceden al conocimiento y aprenden con ellas, y sacan rentabilidad económica con su uso; y por el otro, los grupos que se encuentran excluidos de este acceso tecnológico y las prácticas que posibilita (Olarte Encabo, 2017: 289). Así, "la falta de acceso a las TIC o su pobre uso provoca un efecto de exclusión, de privación de la posibilidad de progreso social, económico y humano que en potencia ofrecen las TIC" (Rogers, 2003; en Cañón Rodríguez, Grande De Prado y Cantón Mayo, 2016: 121).

Hablamos de complejidad en la brecha digital, en tanto no se trata solo de la disponibilidad o carencia de las TD, sino que se haya relacionada estrechamente con aspectos políticos, económicos y sociales como la exclusión social, la precarización laboral, la inequidad en la distribución de la riqueza, el desempleo, etc. (Gómez Navarro, Alvarado López, Martínez Domínguez y Díaz de Leon Castañeda, 2018). 
Poner el foco en esta nueva cara de la desigualdad social nos lleva a advertir la ambivalencia inherente a las TD, en tanto éstas constituyen, como factor de cambio en la economía global basada en el conocimiento y como factor de competitividad, una oportunidad de progreso social, a la vez que un riesgo de profundización en la fragmentación y la desigual distribución de la riqueza (Olarte Encabo, 2017).

Lo expresado anteriormente no es exclusivo del terreno económico en tanto las TD van teniendo una mayor presencia en otras dimensiones sociales. En este sentido, las limitaciones en su acceso pueden restringir o posibilitar la participación de diferentes grupos en la educación, en la cultura, en el ejercicio de la ciudadanía, entre otras. Por lo tanto, al tratarse de artefactos construidos bajo criterios sociales, culturales y políticos, ninguna tecnología es neutral, genera transformaciones en el tejido social, incluye o excluye, condiciona o abre posibilidades. Dicho de otra forma, las sociedades se construyen tecnológicamente, y la tecnología se elabora socialmente (Thomas, Juarez y Picabea, 2015: 11). Así y todo, es este planteo lo que constituye el núcleo del enfoque socio-técnico.

\subsection{Acceso, uso y apropiación: matices en la brecha digital}

Ahora bien, la brecha digital no es un fenómeno homogéneo. En este sentido, para distinguir sus matices y analizarlos, conviene profundizar en tres conceptos claves íntimamente relacionados: el acceso, uso y apropiación.

Sobre el primero, Van Dijk (2017) define a este como un proceso de apropiación de la tecnología que se constituye con las siguientes etapas:

a. el acceso motivacional relacionado con el interés y atracción por la nueva tecnología, lo cual puede ser explicado por factores sociales, culturales, mentales y psicológicos;

b. el acceso físico o material vinculado con la disponibilidad de hardware, software, aplicaciones, redes y el uso de tic y sus aplicaciones;

c. el acceso a la alfabetización digital, vinculado con la educación para adquirir habilidades digitales;

d. el uso referido a las oportunidades significativas de utilización. 
Esta no es la única propuesta posible. Además de la anterior, podemos considerar la desarrollada por Selwyn (2004). Se trata de un modelo lineal que distingue las siguientes fases:

a. acceso, incluye el acceso formal relacionado con la disponibilidad de tic en hogares, escuelas y comunidades para ser utilizadas por todos, así como el acceso efectivo vinculado con la disponibilidad de tic para ser utilizadas por quienes consideran que pueden hacerlo;

b. uso, se refiere al tipo de contacto con las TIC, puede o no ser significativo y puede o no traer consecuencias en el mediano o largo plazo;

c. apropiación, se relaciona con el uso significativo de las TIC, en el que se ejerce un grado de control y elección sobre la tecnología además de los contenidos.

Desde estos modelos visualizamos que no existe un solo concepto y metodología para analizar la brecha digital y sus múltiples aristas. No obstante, nos interesa subrayar que estas herramientas teóricas brindan caminos para tener en cuenta no solo la disponibilidad artefactual, sino también otros factores sociales, culturales, educativos, y por ende, también políticos.

Ahora bien, a lo largo del rastreo bibliográfico, hemos hallado solo dos antecedentes e informes recientes que analizan este fenómeno en la región del NOA. El primero, realizado por García Vargas, Golovanevsky y Chachagua (2015), estudia la brecha digital de los hogares de la región haciendo foco en el acceso y uso desigual de "TIC" que existe entre los diferentes quintiles de las provincias de Salta y Jujuy. El segundo, elaborado por el INDEC (2018), es un informe que expone estadísticas referidas al acceso y uso de tecnologías de la información y la comunicación a nivel nacional. Este se focaliza en el acceso a internet y disponibilidad de computadora en los hogares y el uso de computadora, celular e internet por parte de la población; segmentando la presentación de dichos datos por región, edad, sexo y nivel de instrucción. Todo ello por medio de la Encuesta Permanente de Hogares. De estos, utilizaremos el último, en tanto permite tener la cartografía más reciente respecto al uso y acceso de TD en la región.

A los fines de exponer con mayor claridad los datos de este informe, primeramente, presentaremos un cuadro con algunas cifras relevantes; y posteriormente, realizaremos su interpretación. 
Tabla $\mathrm{n}^{\circ} 1$ : Tasas de acceso a internet y computadora y de uso de computadora, celular e internet en hogares por región

\begin{tabular}{|l|c|c|c|c|c|}
\hline & $\begin{array}{c}\text { Acceso a } \\
\text { internet }\end{array}$ & $\begin{array}{c}\text { Acceso a } \\
\text { computadora }\end{array}$ & $\begin{array}{c}\text { Uso de } \\
\text { computadora }\end{array}$ & $\begin{array}{c}\text { Uso de } \\
\text { celular }\end{array}$ & $\begin{array}{c}\text { Uso de } \\
\text { internet }\end{array}$ \\
\hline NOA & 86,5 & 58,5 & 39,0 & 79,6 & 77,3 \\
\hline NEA & 80,3 & 57,9 & 39,7 & 86,4 & 79,8 \\
\hline Cuyo & 76,6 & 64,6 & 42,4 & 82,6 & 67,5 \\
\hline Pampeana & 78,8 & 61,3 & 43,0 & 83,1 & 78,5 \\
\hline Patagonia & 84,9 & 71,1 & 50,3 & 89,3 & 83,1 \\
\hline GBA & 80,1 & 64,1 & 42,9 & 83,8 & 78,0 \\
\hline $\begin{array}{l}\text { Prom. } \\
\text { Nac. }\end{array}$ & 80,3 & 63,0 & 42,6 & 83,5 & 77,6 \\
\hline
\end{tabular}

Fuente: INDEC (2018).

En este cuadro, puede observarse que la región del NOA presenta índices de acceso y uso de tecnologías digitales por debajo del promedio nacional en casi la totalidad de los factores relevados, excepto en el acceso a internet en los hogares que se sitúa en el 86,5\%, en contraste a la media nacional del 80,3\%. Asimismo, la región muestra índices de uso de computadora $(39,0 \%)$, de celulares $(79,6 \%)$ y de internet $(77,3 \%)$ por debajo de las demás regiones, excepto en el uso de internet donde supera a la región de Cuyo que presenta una tasa del 67,5\%. De este modo, es posible concluir que la región se encuentra marcada por una marcada brecha digital en relación al resto del país.

\subsection{La brecha digital y las PCD}

Ahora bien, y como se explicó anteriormente, esta brecha digital afecta a diversos grupos sociales de formas disímiles. En el caso particular de las PCD, advertimos dos fenómenos contrapuestos.

Por un lado, procesos de inclusión social mediados tecnológicamente que posibilitan la participación y autonomía de las PCD en diversas dimensiones sociales. Podemos señalar los casos del uso de dichas tecnologías en la 
educación, en el empleo, en las finanzas y en el comercio, en el gobierno electrónico y en la participación ciudadana, en la cultura y en el turismo, por mencionar algunas (Raja, 2016). De esta manera, el acceso a estas tecnologías conlleva una mejora en la calidad de vida y el aumento de la autoestima de las PCD; potenciando su desarrollo personal; favoreciendo a su inclusión social y la vida independiente (García Bilbao y Rodríguez-Porrero, 2000).

De forma opuesta, y hasta paradójica, surgen en esta brecha digital procesos de exclusión definidos por la ausencia de dispositivos, servicios web y aplicaciones construidas socialmente bajo los principios de accesibilidad y diseño universal, como así también la escasez de formación y preparación del entorno (Ferreira y Díaz Velásquez, 2009). Esto último se constituye en una nueva barrera social que vulnera los derechos del colectivo en tanto limitan la participación social e impiden el ejercicio y el acceso a otros derechos.

Al profundizar en este fenómeno en la región del NOA, advertimos que no existen investigaciones e informes relevantes. No obstante, al mirar el escenario nacional y latinoamericano, es posible encontrar diversos trabajos que concluyen en la siguiente afirmación: las PCD poseen un menor acceso a las TD que las personas que no tienen discapacidad.

En el primer grupo, se destaca un informe alternativo referido al cumplimiento de la "Convención sobre los Derechos de las Personas con Discapacidad” (de ahora en más CDPD o Convención) presentado por diferentes ONG que nuclean al colectivo (ONU, 2017). Este no ofrece estadísticas pero sostiene que los sitios en internet del Estado no cumplen con la legislación, siendo en su mayoría construidos sin las pautas de accesibilidad. Esta afirmación se respalda en numerosos trabajos de investigación que hemos recopilado en un escrito previo (Soto, 2017: 194-195). Por su parte, los informes elaborados por el Estado argentino (ONU, 2011; OEA, 2016) tampoco muestran índices de acceso a las tecnologías digitales por parte de las personas con discapacidad. No obstante, describen políticas públicas que van más allá de las transformaciones en el terreno legislativo. Es decir, describen planes y programas orientados a la formación para el diseño de sitios webs accesibles (Programa Atedis), entrega de equipamiento para personas con discapacidad en diferentes niveles educativos, y elaboración de materiales didácticos digitales accesibles para las escuelas (Programa Conectar Igualdad y Programa PODES).

En el terreno latinoamericano, un informe elaborado por Hernán Galperín (2017: 14) para la UNESCO, afirma que existe, en los países donde hay datos 
disponibles, "una brecha significativa en términos de acceso residencial en los hogares cuyo jefe tiene algún tipo de discapacidad (entre 6 y 30 puntos porcentuales según el país)". Respecto al uso de internet, observa que las PCD tienen una probabilidad casi 5 veces menor de estar conectadas respecto a las personas sin discapacidad.

\section{La discapacidad como categoría social y política}

Para comprender este escenario social desde una perspectiva crítica que permita visualizar los elementos que configuran la exclusión de las PCD y explicitar nuestro posicionamiento sobre la discapacidad, conviene recuperar algunos planteos de uno de los modelos teóricos que la explican. Puntualmente, el modelo social anglosajón de la discapacidad (Oliver, 1998).

Desde este posicionamiento, nacido en Gran Bretaña en la década de los setenta, basándose en el materialismo histórico del marxismo, se sostiene que la discapacidad es una categoría social y política, es decir que no son las deficiencias biológicas o físicas suscriptas a la corporalidad individual las que conforman la discapacidad, sino que se trata de una construcción social definida por un complejo haz de barreras que impiden y o limitan la participación del colectivo (Oliver, 1998; Palacios, 2017). De este modo, la discapacidad debe ser comprendida holísticamente ya que en ella confluyen una serie de dimensiones entre las que se destacan las barreras económicas, medioambientales y culturales en el contexto. Entre estas últimas, se distinguen de forma pormenorizada la inaccesibilidad a la educación, a los sistemas de comunicación e información, a los entornos laborales, al transporte, a las viviendas y los edificios públicos, o a los servicios de salud, etc. (Victoria Maldonado, 2013: 1098).

Esta diferenciación entre la deficiencia y la discapacidad del modelo social permitió, primeramente, plantear una teoría de la opresión de la discapacidad. Esta afirma que la opresión creada por la discapacidad se expresa en las interacciones cotidianas "en donde la estigmatización clasifica a las PCD como desafortunadas, inútiles, diferentes, oprimidas y/o enfermas; en la estratificación social y en el espacio físico" (Ferrante, 2014: 40). Esta teoría de la opresión de la discapacidad se inspira en la opresión que sufren las clases obreras en el marxismo.

En segundo lugar, el modelo social posibilitó cuestionar y dejar de lado aquellos otros modelos que atribuían las causas de la discapacidad y su 
exclusión en el sujeto. Es decir, la discapacidad no es producto de una maldición o el pecado (modelo de prescindencia), una tragedia personal, una enfermedad incurable que debe tratarse permanentemente (modelo médico o rehabilitador), sino la falta de condiciones sociales -materiales, culturales e ideológicas- que posibiliten la participación de sujetos con una corporalidad alejada de los criterios de normalidad en la vida social. Cabe destacar que dichos criterios, desde el modelo aquí explicado, son fijados por el sistema capitalista por lo que se trataría de una normalidad que establece como ideal un cuerpo eficiente capaz de ser explotado en los procesos de producción.

Por último, emerge de este modelo una concepción de las PCD como sujetos de derecho, donde estas pueden aportar a la sociedad de diferentes formas y de igual modo que las personas que no tienen discapacidad, mediante las condiciones apropiadas del entorno. De esta forma, no son las personas con deficiencias las que deben rehabilitarse para recuperar las funciones perdidas o alcanzar los mencionados criterios, sino que es la sociedad la que debe brindar las condiciones de acceso para procurar la plena inclusión de las PCD a la educación, al trabajo y a otros derechos.

Este modelo teórico no fue ni es el único que elabora una explicación sobre esa construcción social denominada "discapacidad". Existen otros desarrollos previos como el Movimiento de Vida Independiente que se desarrolló en sintonía a otros movimientos sociales en la década de los sesenta en los Estados Unidos. Este modelo puso énfasis en la defensa de la libre elección y el control de las PCD sobre sus propias vidas. En este sentido, "la independencia ya no debía medirse en relación a la cantidad de tareas que pueden realizarse sin asistencia, sino en relación a la calidad de vida que se podía lograr con asistencia" (Palacios, 2008: 113).

El denominado "movimiento de vida independiente" se opuso al dominio profesional y a la provisión burocrática de los servicios sociales y su escasez, mientras demandaba oportunidades para que las mujeres y hombres con diversidad funcional desarrollaran sus propios servicios en el mercado. De esta manera, replicó las piedras angulares de la sociedad americana: capitalismo de mercado, independencia, libertad política y económica. Esto acentuó los derechos civiles, el apoyo mutuo, la desmedicalización y la desinstitucionalización (Palacios y Romañach, 2006: 50). 
Pero este movimiento no ha estado libre de críticas. Así, para los partidarios de centro izquierda del modelo social anglosajón, este movimiento reproduciría la ideología de los promotores del desarrollo capitalista, por lo que naturalizaría el conjunto de prácticas que oprimen no solo a las PCD sino también a otros grupos sociales entre los que se pueden mencionar las mujeres, minorías étnicas, homosexuales y personas mayores. Asimismo, desde esta crítica se ha señalado que el concepto de vida independiente resulta conceptualmente impreciso en tanto todos los humanos son por definición seres "sociales" y que todos los seres humanos, independientemente del grado y naturaleza de su discapacidad, son interdependientes (Palacios, 2008: 119).

Más allá de estos cuestionamientos, cabe señalar que muchos de los elementos del "movimiento de vida independiente" sirvieron de inspiración al modelo social en tanto la crítica a la medicalización e institucionalización permitió cuestionar los modos en que los Estados reafirmaron el modelo médico y rehabilitador sobre las PCD; y la defensa de los derechos civiles se constituyó en uno de los gérmenes que inspiraría el pasaje del modelo social al paradigma de los derechos humanos décadas más tarde, tema que abordaremos posteriormente. Asimismo, este movimiento inspiraría otros desarrollos particulares en países como España, donde se harían planteamientos novedosos sobre la discapacidad como su giro teórico a la "diversidad funcional", con una marcada defensa a la diversidad corporal desde fundamentos bioéticos, y los postulados de la "filosofía de vida independiente" (Palacios y Romañach, 2006: $60)$.

Así y todo, tomamos en este trabajo como punto de partida el modelo social anglosajón, sin dejar de realizar una vigilancia epistemológica sobre el mismo. $\mathrm{Al}$ respecto, éste ha recibido diferentes críticas durante los últimos veinte años, las que no podremos explicar a profundidad en tanto escapan a los objetivos de este trabajo. Pero que resultan importantes de reseñar, no solo para mostrar sus límites, sino también nuevas perspectivas teóricas a partir de la superación de los mismos (Ferrante, 2014).

La existencia de un determinismo biológico sobre la deficiencia: esto olvida que las percepciones y acciones sobre el cuerpo también son construcciones sociales; recuperar la dimensión social de la deficiencia, no solo rompe con la oposición entre deficiencia y discapacidad, sino que permite observar la gestión política sobre las corporalidades. 
La invisibilización de la experiencia de la deficiencia: las PCD viven a diario una exclusión en la interacción con otras corporalidades sin deficiencias; sumergirse en ella también posibilita conocer otros modos en los que se ejerce la dominación a nivel subjetivo e intersubjetivo.

La concepción de la opresión como un fenómeno mecanicista: la dominación no es automática, no se ejerce de la misma manera sobre todas las PCD, depende de las condiciones sociales que la constituyen; esto posibilita observar diferentes modos de dominación y también otros modos de resistencia.

\subsection{Del modelo social al paradigma de los Derechos Humanos}

El modelo social de la discapacidad, construido, defendido y apoyado políticamente por las organizaciones de las PCD, dio origen al paradigma de Derechos Humanos. Este último ha inspirado "el surgimiento de documentos internacionales que, ante la persistencia de situaciones de discriminación y trato injusto hacia las PCD, buscan promover su respeto" (ONU, 2006, en Ferrante, 2015: 153). A partir de este paradigma y tras muchas décadas de lucha política, el 13 de diciembre de 2006, la Asamblea General de la Organización de las Naciones Unidas firma uno de los documentos más relevantes para la reivindicación de los Derechos Humanos del colectivo: La CDPD.

Desde este instrumento legal, y en coincidencia con el modelo social, la discapacidad es comprendida como el resultado de la interacción entre una persona con cierta deficiencia y las barreras sociales que impiden la participación en igualdad de condiciones con las demás (ONU, 2006). Es por ello que hablamos de "Personas con Discapacidad" debido a que se busca poner en primer lugar el carácter de sujeto de derecho (persona) y la discapacidad como una condición externa (con discapacidad).

En términos generales, a partir de este instrumento los Estados firmantes se comprometen a "promover, proteger y asegurar el goce pleno y en condiciones de igualdad de todos los derechos humanos y libertades fundamentales por todas las PCD, y promover el respeto de su dignidad inherente" (ONU, 2006: 4). Así, estos deben garantizar el acceso de las PCD a la educación, al trabajo, a la salud, a la justicia, a la información, a los espacios físicos, a la movilidad, entre otros; respetando la dignidad, libertad, autonomía, igualdad de oportunidades, y la no-discriminación. 
Entre los principios declarados en la Convención, interesa poner el acento en la accesibilidad universal y diseño universal, en tanto se conforman en los elementos imprescindibles para crear entornos socio-técnicos libres de barreras. Al respecto, advertimos que la accesibilidad universal es la cualidad o característica que tiene que tener un entorno, producto o servicio para ser utilizado por cualquier persona, incluyendo a las que tienen discapacidad, sin presentar ningún tipo de restricción, condicionamiento o limitación (INADI, 2012).

Por su parte, el diseño universal busca la creación de entornos y productos con un proceso planificado de elaboración para que sean utilizados por la mayor cantidad de personas sin distinción alguna, con características que deben tener para que sean más accesibles al valorar la diversidad y la inclusión (Delgado Vargas, 2017: 4; Urroz, 2015: 39-40).

De forma más precisa, la Convención garantiza el acceso a las TD y establece la necesidad de un diseño y desarrollo apropiado de las mismas, mediante los siguientes incisos en su Artículo 9:

g) Promover el acceso de las PCD a los nuevos sistemas y tecnologías de la información y las comunicaciones, incluida Internet; h) Promover el diseño, el desarrollo, la producción y la distribución de sistemas y tecnologías de la información y las comunicaciones accesibles en una etapa temprana, a fin de que estos sistemas y tecnologías sean accesibles al menor costo.

Además de la normativa antes señalada, es necesario aclarar que en el campo de las TD aplicadas a la web existen las Pautas de Accesibilidad al Contenido Web, normas WCAG por sus siglas en inglés. Estas buscan garantizar un acceso universal a la web, independientemente del tipo de hardware, software, infraestructura de red, idioma, cultura, localización geográfica, y capacidades de los usuarios. De esta forma, esto no hace referencia solo a los usuarios con discapacidad, sino que también se dirige a resolver cualquier problema que impida el acceso a los contenidos de la web por parte de cualquier usuario (Fernández Díaz, Jambrino Maldonado, 2019: 47).

Ahora bien, es innegable que la Convención se constituye en una herramienta fundamental en la lucha por la reivindicación de los Derechos Humanos de las PCD. No obstante, y como señala Carolina Ferrante (2015: 154), tras una extensa revisión bibliográfica, muestra que: 
Muchos autores han señalado la distancia entre la "posición asumida [por la Convención] y la efectiva implementación” (Courtis, 2009: 412; Acuña y Goñi, 2010; Vite Pérez, 2012; Pantano, 2009), la inconsistencia entre la Convención y las leyes vigentes sobre discapacidad a nivel nacional ( Joly, 2008; Brogna, 2012; Ferrante, 2013), la necesidad de trasladar el debate de la razón jurídica a la ética (Skliar, 2010; Pantano, 2009; Arteaga y Dyjak, 2006), la vigencia de los esquemas de percepción del pasado en el presente (Brogna, 2009, 2012; Ferrante, 2012) y la proliferación de dispositivos de inclusión excluyente y nuevas formas de vulnerabilidad (Almeida, 2009; Vite Pérez, 2012).

Todo esto se traduce en una exclusión latente que viven las PCD en lo cotidiano y que se manifiesta en la imposibilidad de acceder a una educación inclusiva, a un empleo, a llevar adelante un proyecto de vida con autonomía, lo que lleva a su vez a experimentar una marcada precarización socio-económica.

\subsection{E1 valor de la Educación Inclusiva para las PCD}

Resulta importante señalar que el acceso a la educación de las PCD, históricamente vulnerado en las sociedades occidentales por la existencia de procesos de exclusión y segregación de la escuela común, constituye, junto a un derecho humano básico, un capital clave en las posibilidades futuras de inclusión en el mundo del empleo, ámbito por el cual también este sector de la población ha sido fuertemente rezagado y caracterizado por mayores niveles de desempleo crónico, inactividad e informalidad respecto a las personas sin discapacidad. Esta situación propicia que las PCD presenten más dependencia, mayores niveles de pobreza y una calidad de vida más deteriorada que el resto de la población (OMS, 2011). Es por esto, que las tendencias actuales, buscan propiciar la educación inclusiva, para revertir círculos viciosos y excluyentes. Entenderemos aquí a esta última como un modelo de prácticas y saberes que busca garantizar el derecho a la educación de los grupos excluidos del sistema escolar, de la escuela común o segregados en instituciones "especiales", y que tiene como objetivo una educación común para todos/as. Se presupone que "la educación inclusiva tiene por objeto eliminar la exclusión social que es una consecuencia de las actitudes y respuestas a la diversidad de raza, clase social, origen étnico, religión, género y capacidades" (Vitello y Mithaug, 1998, en Ainscow y Miles, 2008: 18). En este sentido, se considera a la educación inclusiva no como un fin en sí misma, "sino un medio para alcanzar un fin, el del establecimiento de una sociedad inclusiva” (Cobeñas, 2014). 
La Convención en su artículo 24 recupera este derecho y establece que los Estados que suscriban a la misma se comprometen a garantizar que las PCD no queden excluidas del sistema general de educación por motivos de discapacidad. Esto implica que los niños y jóvenes con discapacidad tienen derecho a una primaria y secundaria inclusiva, de calidad y gratuita, en igualdad de condiciones con las demás, en la comunidad en que vivan; que se realicen ajustes razonables en función de las necesidades individuales; se faciliten medidas de apoyo personalizadas y efectivas en entornos que fomenten al máximo el desarrollo académico y social; y que se brindará a las PCD la posibilidad de aprender habilidades para la vida y desarrollo social, a fin de propiciar su participación plena y en igualdad de condiciones en la educación y como miembros de la comunidad (ONU, 2006: 19).

Sin embargo, pese al reconocimiento formal, en las prácticas las políticas educativas no contemplan a las PCD o las mismas no se hacen cumplir de forma efectiva, lo que conlleva a que los niños y jóvenes con discapacidad tengan menos probabilidades que sus homólogos sin discapacidad de ingresar y permanecer en la escuela. De hecho, la posibilidad de implementación de este derecho ha sido señalada como uno de los derechos más difíciles de concretar a nivel global por Naciones Unidas (Palacios, 2017).

En el caso local, "el Estado Argentino incumple su obligación internacional de garantizar el derecho de las PCD a una educación inclusiva asentados en los principios generales de la CDPD" (Ferrante, 2017). Si bien la Ley Nacional N ${ }^{\circ}$ 26.206 de Educación Nacional del 2006 y la reciente normativa del Consejo Federal de Educación (Res. 311/2016) trae avances en la regulación de la trayectoria educativa de las PCD al poner al nivel secundario como obligatorio y al brindar garantías para la certificación del nivel, respectivamente; estas no se encuentran plenamente armonizadas con los postulados de la CDPD", puesto que establecen que las jurisdicciones provinciales deben garantizar el funcionamiento de la modalidad especial, un sistema paralelo, excluyente y estigmatizador para las PCD. Así, estas normas son la expresión de un paradigma segregador y su vigencia es incompatible con la obligación de los Estados de garantizar el derecho a la educación inclusiva (Faica et al, 2018: 22).

Así pues, esta investigación hará foco en el nivel de la educación secundaria, no solo debido a las transformaciones normativas ya indicadas, sino que además en este espacio se han visibilizado situaciones de exclusión entre las que 
podemos señalar: la negativa de las instituciones educativas a recibir a estudiantes con discapacidad alegando falta de preparación en las instalaciones y/o formación en la temática de la discapacidad, o a entregar el título de aprobación del nivel secundario, afirmando que el estudiante transitó por la institución pero no adquirió el conocimiento establecido por el currículo (Cobeñas, 2015). Asimismo, la experiencia escolar para las PCD, y sobre todo para jóvenes mujeres, resulta discapacitante, opresiva y deshumanizante, y que esto es particularmente doloroso en aquellas situaciones en que les son negadas formas de comunicación acorde a sus posibilidades. Incluso, en aquellas prácticas denominadas como inclusivas por el sistema educativo se dan múltiples situaciones en que los y las alumnos/as con discapacidad sufren tratos violentos, subalternizantes, inferiorizantes y discapacitantes (Cobeñas, 2016: 217-218).

Cabe señalar que los antecedentes aquí indicados hicieron foco en las instituciones educativas de la región central del país, puntualmente en la provincia de Buenos Aires. En cuanto a nuestra región de interés, solo hemos podido hallar una investigación en curso realizada por Natalia Barrozo (2018). $\mathrm{Al}$ respecto, esta se propone indagar en las trayectorias educativas de Estudiantes con discapacidad en el nivel secundario de la provincia de Salta. La misma se encuentra en desarrollo y no posee conclusiones definitivas, pero sí una profundización teórica relevante y una aproximación empírica. Esto nos brinda herramientas teóricas para realizar una breve cartografía del contexto educativo por el que transitan los estudiantes con discapacidad y nos ofrece como camino empírico posible indagar en las prácticas de los Centros de Educación Integral para jóvenes con discapacidad de la provincia de Salta. No obstante, consideramos conveniente profundizar en estos aspectos en trabajos posteriores.

\section{Los aportes de las TD en los espacios educativos para las PCD}

Tomamos como punto de partida reconocer la complejidad en la relación entre educación y tecnología. Es decir, que la misma involucra diversos factores por lo que la inclusión de las TD en el aula posee diversos obstáculos que van más allá del acceso artefactual y de las infraestructuras de conexión (Coll, 2009: 117).

De esta forma, para desplegar las potencialidades de transformación de estas tecnologías se requiere un análisis y reflexión en torno a su orientación pedagógica y su contexto de uso. Es decir, qué se quiere enseñar, con qué tipo 
de herramienta y cuáles son las condiciones sociales y culturales que rodean ese acto educativo. Con este posicionamiento buscamos evitar caer tanto en un determinismo tecnológico como en uno pedagógico, por el cual con solo transformar la perspectiva pedagógica sobre las tecnologías - de prácticas con fundamentos tradicionales a constructivistas- se mejorará la educación por medio de estas.

En primer lugar, las TD pueden tomar el papel de herramientas psicológicas susceptibles de mediar los procesos inter e intra-psicológicos implicados en la enseñanza y el aprendizaje. En segundo lugar, transformarse en mediadoras dentro del triángulo interactivo compuesto por los estudiantes, los profesores y los contenidos, contribuyendo a conformar el contexto de actividad en el que tienen lugar estas relaciones.

Cabe señalar que la potencialidad mediadora de las TD se hace presente cuando son utilizadas por alumnos y profesores para planificar, regular y orientar las actividades propias y ajenas, introduciendo modificaciones importantes en los procesos intra e inter-psicológicos implicados en la enseñanza y el aprendizaje (Coll, 2009: 120).

Son las características de estas tecnologías las que posibilitan la ubicuidad del aprendizaje, la interactividad entre estudiantes, contenidos y docentes, los materiales didácticos hipermediales, los entornos personales de aprendizaje, las comunidades de práctica y aprendizaje, espacios de afinidades, entre otros. Todos ellos espacios educativos con otros modos de organización pedagógica, con otros roles y formas de ser docente y estudiante, con otras nociones de cultura y formas de producir y compartir el conocimiento, que poseen diferencias marcadas con las formas tradicionales del espacio escolar y los modos en que se estructuran las actividades educativas (Dussel y Quevedo, 2011: 32).

Ahora bien, ¿cómo pueden aportar estas tecnologías a los procesos de educación inclusiva de las PCD? Para responder esta pregunta expondremos una taxonomía basada en las formas en que favorecen la accesibilidad en tres dimensiones: comunicacional, física y a los artefactos culturales. Esta división no se estructura en espacios estancos, sino más bien dinámicos que interactúan y se retroalimentan mutuamente. Asimismo, con esto pretendemos alejarnos de aquellas formas de clasificar a estas tecnologías por el tipo de supuesta "deficiencia" que atenderían; lo cual desde la perspectiva epistemológica de la 
discapacidad en la que nos posicionamos volvería a reafirmar el efecto normalizador y compensador del modelo médico. Así, buscamos poner el acento en como favorecen la accesibilidad, uno de los principios de la CDPCD, en los espacios educativos. Es importante también mencionar que estos aportes a la accesibilidad no son solo aprovechables por las PCD sino también por diversos colectivos sociales que históricamente han sido marginados de los espacios educativos.

\subsection{Accesibilidad comunicacional}

En primer lugar, la característica de mediación y de intercambio y traducción semiótica de estas tecnologías aporta al ejercicio de otros modos de comunicación que exceden los límites planteados por el uso exclusivo del lenguaje oral, constituido por signos sonoros de la voz humana, o el escrito y/o visual, basados en la representación de signos gráficos y las imágenes analógicas; modos que aún tienen un papel preponderante en las aulas. Así, este grupo social ha sido excluido históricamente de participar en estos sistemas culturales, debido a que la diversidad visual, auditiva o cognitiva no ha sido tenida en cuenta para la comunicación en el aula.

Cabe destacar que la comunicación resulta imprescindible para las actividades educativas en tanto los procesos de enseñanza y aprendizaje son un tipo específico de procesos comunicativos que solicitan a los participantes la elaboración, el entendimiento y la comprensión de mensajes, los cuales se construyen por medio del lenguaje. Este último, se constituye en el vehículo predominante por el cual se trasmite información y conocimiento, se piensa y se aprende la realidad, se construyen consensos y significados comunes, se median los conflictos, es decir, es una acción social. Así pues, la actividad educativa es una acción en donde el entendimiento lingüístico interviene como un principal elemento para la estructuración de las interacciones y solo puede lograr su finalidad primordial si se le entiende y se desarrolla como una acción comunicativa, es decir, como una acción social mediada por el lenguaje orientada al entendimiento (Banderas Martínez, 2014: 57).

Las TD pueden aportar a estos procesos por medio de favorecer otros modos de comunicación. Así, con ellas es posible construir o brindar soporte a sistemas de comunicación aumentativa y/o alternativa. Esta comunicación se define como "el conjunto estructurado de códigos (verbales y no verbales), expresados a través de canales no vocales (gestos, signos, símbolos gráficos), 
necesitados o no de soporte físico, los cuales mediante procesos específicos de instrucción, sirven para llevar a cabo actos de comunicación (funcional, espontánea y generalizable) por sí solos o en conjunción con códigos vocales, o como apoyo parcial de los mismos" (Sánchez Montoya, 2016: 14).

En un plano de aplicación, por medio de un software puede configurarse un tablero interactivo de comunicación en el que se pueden introducir pictogramas estandarizados, imágenes y símbolos. La combinación y estructuración dinámica de estos signos visuales en la pantalla le permiten al estudiante y al docente construir y recibir mensajes, y de esta forma, derribar las barreras que presenta el uso exclusivo del lenguaje oral para las PCD.

Por su parte, existen programas que posibilitan la accesibilidad comunicacional cuando las limitaciones están dadas por el uso exclusivo del lenguaje visual o el lenguaje escrito dentro de un entorno digital. Estos, denominados "lectores de pantalla", realizan una interpretación de los diferentes elementos visuales de la interfaz gráfica de los sistemas operativos, para luego trasmitirla mediante síntesis de voz o línea Braille al usuario. Es decir, la aplicación interpreta de forma sonora o táctil los íconos, botones y textos de una pantalla, lo que implica que un usuario con discapacidad visual pueda manejar una PC de forma autónoma sin la necesidad de un entorno gráfico (Soto y Lacuadra, 2017: 6; Labrada-Martínez, 2011).

En el caso de que la barrera esté constituida por el lenguaje escrito de forma analógica, por ejemplo un libro de papel, es posible utilizar los reconocedores ópticos de caracteres, llamados OCR por sus siglas en inglés, los cuales permiten transformar los caracteres analógicos a digitales. De esta forma, una vez hecha esta conversión a texto digital, pueden emplearse los lectores de pantalla ya mencionados para leer el texto en la computadora. También es posible transformar dicho texto en una pista sonora con voz, mediante un software de texto a voz, o sistema TTS por sus siglas en inglés, para ser escuchado en otros dispositivos digitales.

\subsection{Accesibilidad física}

Ahora bien, y en cuanto a esta dimensión, estas tecnologías aportan en la medida en que pueden acortar las distancias espaciales o las barreras que plantean, paradójicamente, el hardware de los dispositivos digitales. Esto último se debe a que la mayoría de los periféricos de entrada (teclado, ratón o pantalla 
táctil) exigen a los usuarios la movilidad y la motricidad fina de las manos, lo cual excluye a quienes corporalmente escapan de la "normalidad".

En cuanto a lo primero, y relacionado estrechamente con lo anterior, señalamos aquí a la generación de entornos comunicativos que abren nuevas posibilidades de participación y socialización de los estudiantes con discapacidad dentro del proceso educativo, que extienden el espacio de aprendizaje por fuera del aula y reducen los desplazamientos físicos. Hacemos referencia, puntualmente, a las video conferencias para la explicación de contenidos, los debates a través de los foros, el correo electrónico como herramienta de comunicación en las tutorías, el chat como medio de socialización con el resto de compañeros, los mensajes de texto para comunicaciones puntuales o las redes sociales (Vázquez Cano, 2012: 75).

Respecto a las barreras que presenta el hardware estandarizado, existen un conjunto de aplicaciones y periféricos específicos que posibilitan el uso de estas tecnologías por parte de usuarios con discapacidad motriz.

En primer lugar, se destacan aquí los "reconocedores de voz" que posibilitan el uso del ordenador por medio de instrucciones vocales. Con este tipo de software el usuario, al expresar de forma oral un grupo de comandos, puede ejecutar un programa, navegar por internet, escribir un texto mediante el dictado, entre otras tareas.

En segundo lugar, encontramos a los "emuladores de ratón", una combinación de software y hardware, que permiten controlar el puntero por medio de otras partes del cuerpo. Dentro de este grupo, se encuentran los joystick que permiten realizar operaciones con las palmas de las manos, las interfaces oculares que se sirven exclusivamente de los movimientos de los ojos, las binchas que se alimentan de los movimientos del rostro y la cabeza, o inclusive, sorbetes que reciben instrucciones de los movimientos de la boca y la lengua (Mejía Díaz, 2018).

En tercer lugar, podemos señalar a los teclados virtuales, que en combinación con los sistemas anteriores, posibilitan realizar las operaciones asociadas al teclado mediante el puntero y cuyo manejo está sujeto a su visualización en la pantalla. 


\subsection{Accesibilidad a los artefactos culturales}

Los artefactos culturales son piezas básicas del engranaje del ser humano con el mundo físico y de las personas entre sí. Un rasgo esencial es su apertura o bifrontalidad: son al mismo tiempo materiales e ideales (es decir, conceptuales o simbólicos), es decir, tienen una base tangible pero a la vez son intangibles, porque funcionan creando y adquiriendo significaciones (Martos, y Martos García, 2014: 122).

De esta manera, dichos artefactos no son sólo objetos estáticos. En sî mismos están histórica y culturalmente situados, cargando saberes, posibilidades y distintos lenguajes para pensar y actuar.

Constituyen "andamios" (sostén o puntos de apoyo) para el aprendizaje, en el pensamiento y en la acción. Algunos de ellos, como los libros, los videos y las herramientas informáticas, presentan distintos lenguajes y formas de representación, ampliando la comprensión cultural y las habilidades cognitivas (Perkins, 1986, en Davini, 2008: 35).

Es necesario aclarar que bajo esta propuesta teórica las TD pueden convertirse en soporte a un artefacto cultural o darle acceso, pero no todas las TD serían artefactos culturales. Ponemos como ejemplo a un microtransistor que podría procesar, transportar o reproducir o representar un lenguaje multimedia, pero bajo la ausencia de esta tarea se convertiría en una pieza de silicio, lo que no invalida que su creación sea un producto social.

Así, en esta dimensión, no solo se pueden señalar los casos de la digitalización de textos, que ya hemos revisado en el apartado de la accesibilidad comunicacional, y que sin lugar a dudas podría también incluirse aquí. Más bien nos interesa señalar otros artefactos que sirven de apoyo al aprendizaje y que tienen su existencia en un entorno digital. En este sentido, podemos reseñar los aportes de los materiales didácticos hipermediales, la realidad aumentada, los entornos virtuales de aprendizaje, por mencionar algunas posibilidades.

Un material didáctico hipermedial (MDH) es un objeto de aprendizaje que responde a una secuencia y a los objetivos pedagógicos previstos para enseñar un contenido a un destinatario. La finalidad de estos últimos no es solo transmitir una información a cierto tipo de público utilizando las propiedades del lenguaje multimedia sino que el lector/usuario aprenda y comprenda las 
temáticas trabajadas en él (Landau, 2006 en Landau, 2013). Lo didáctico estará constituido mediante las siguientes funciones: ser organizador teórico de la información, constituirse en una herramienta de diseño y poseer una estructura completa (Lamarca Lapuente, 2008 en Landau, 2009). Estos hipermedia didácticos, además de desplegarse en internet, tienen como características ofrecer una estructura compleja que se presenta como abierta e incompleta, lo que permite articular elementos dentro y fuera del propio material didáctico. También poseen una cantidad importante de conexiones subjetivas, es decir, enlaces cuya relación no es explícita y requiere ser repuesta por el lector, acompañadas de huellas de lectura que funcionan como orientadoras para los estudiantes (Landow, 2009).

A partir de las características de estos objetos, y a diferencia de otros objetos de aprendizaje, es posible: brindar al estudiante con discapacidad un entorno para realizar su propio recorrido respetando su ritmo de aprendizaje; realizar ajustes o ampliaciones del contenido para hacerlo más comprensible mediante el potencial del hipermedia; intercambiar o mezclar el lenguaje utilizado para ofrecer mayor inteligibilidad; por mencionar algunos aspectos relevantes.

$\mathrm{Si}$ bien los $\mathrm{MDH}$ se expresan generalmente en una pantalla, es posible trasladar muchas de sus propiedades al aula mediante la realidad aumentada. A grandes rasgos, esta consiste en enlazar información hipermedia a los entornos reales mediante tecnología digital. En el ámbito educativo, implica tener la posibilidad de añadir información extra al proceso de aprendizaje, lo que se traduce en poder agregar videos, audio, animaciones, modelos tridimensionales y diferentes contenidos digitales durante el dictado de clases en el aula.

Para Cabezas (2016: 30) el uso de la realidad aumentada puede mejorar la eficiencia de los procesos de enseñanza-aprendizaje y a ayudar a la inclusión en el marco educativo, ya que es una tecnología que tiene la habilidad de proveer la información correcta que se requiere en un punto temporal particular de este proceso de aprendizaje. Esto ofrece al estudiante con discapacidad no solo mayor información sino también un mayor control de su proceso de aprendizaje, lo que resulta fundamental en un proceso de educación inclusiva.

Por último, reseñaremos aquí a los Entornos Personales de Aprendizaje, o PLE por sus siglas en inglés (Personal Learning Environment); los cuales pueden aportar también a ese mayor control del aprendizaje. Al respecto, un PLE se constituye en un entramado de herramientas, fuentes de información, 
conexiones y actividades que cada persona utiliza de forma asidua para aprender en la red. En este sentido, incluye tanto aquello que una persona consulta para informarse, las relaciones que establece con dicha información y entre esa información y otras que consulta; así como las personas que le sirven de referencia, las conexiones entre dichas personas y él mismo, y las relaciones entre dichas personas y otros que a la larga pueden resultarle de interés; y, por supuesto, los mecanismos que le sirven para reelaborar la información y reconstruirla como conocimiento, tanto en la fase de reflexión y recreación individual, como en la fase en la que se ayuda de la reflexión de otros para dicha reconstrucción.

Entonces, podemos afirmar que un PLE se estructura en torno a aquellas herramientas que nos permiten tres procesos cognitivos básicos: leer (en el sentido más amplio de la palabra), reflexionar y compartir. Por todo esto, incluiríamos en nuestro PLE básico esencialmente tres tipos de elementos:

a. herramientas y estrategias de lectura: las fuentes de información a las que accedo que me ofrecen dicha información en forma de objeto o artefacto;

b. herramientas y estrategias de reflexión: los entornos o servicios en los que puedo transformar la información (sitios donde escribo, comento, analizo, recreo, publico);

c. herramientas y estrategias de relación: entornos donde me relaciono con otras personas de/con las que aprendo.

En término de posibilidades, por medio de la construcción de un PLE un estudiante con discapacidad puede buscar información expresada en diferentes sistemas semióticos acorde a su interés, saltando de este modo las barreras a la comunicación; crear sitios y materiales multimedia para compartir su conocimiento y experticia; intercambiar con otros estudiantes experiencias de aprendizaje significativas y conocimientos para solucionar problemas o resolver inquietudes, por mencionar algunas de ellas.

\subsection{Las TD como barreras a la enseñanza y al aprendizaje}

Dicho todo esto, resulta importante tener en cuenta que estas posibilidades ya descriptas en estas tres dimensiones de accesibilidad (comunicacional, física y pedagógica) pueden ser limitadas u obstaculizadas si la interfaz o equipamiento no es diseñado bajo principios de accesibilidad o diseño universal (Luque Parra 
y Rodríguez Infante, 2009). Partiendo de un equipamiento estándar, tanto en ordenador de sobremesa como en portátil, pueden identificarse algunas barreras dependiendo del tipo de discapacidad.

a. Discapacidad visual: preponderancia del entorno visual, carencia de sistemas de amplificación del entorno gráfico, lectura de pantalla o sistemas táctiles.

b. Discapacidad motriz: sistemas de entrada e interacción que requieren motricidad fina, baja disponibilidad de hardware de apoyo.

c. Discapacidad auditiva: entornos con preponderancia del sistema de lenguaje escrito, desarrollados sin lengua de señas, videos con subtítulos o indicaciones icónicas visuales.

d. Discapacidad intelectual: entornos complejos o que implican actividades cognitivas de nivel abstracto. Carencia de alternativas de uso simplificado o de fácil comprensión.

Más allá de estas limitaciones o barreras, existe un consenso generalizado en afirmar que las TD ofrecen gran versatilidad para la atención a la diversidad. Así, puede destacarse el papel importante que juegan en favorecer la estimulación y atención a sus necesidades en: la ampliación de las oportunidades en el proceso de enseñanza-aprendizaje, la facilitación del aprendizaje lectoescritor; la comunicación y el lenguaje; el aumento de la autoestima y la motivación y de la inclusión social, entre otros (Silva Sandez y Rodríguez Miranda, 2018).

Es por todo lo explicado en este apartado que consideramos pertinente indagar en trabajos posteriores sobre los modos de intervención del Estado para favorecer el acceso a estas tecnologías. Lo que implica profundizar en las políticas públicas orientadas a la inclusión digital de las PCD en los espacios educativos del país y de la región NOA.

\section{Conclusiones}

El trayecto realizado hasta aquí permite observar los diferentes elementos teóricos que estructuran el objeto de estudio propuesto como así también dar cuenta de diversos hallazgos en relación al mismo. 
Primeramente, podemos destacar las particularidades de la brecha digital que experimentan las PCD, donde no solo interactúan los elementos que componen la brecha digital de la población en general (factores económicos, culturales, educativos y demográficos), sino que también intervienen otros provenientes de las barreras sociales que constituyen y profundizan la discapacidad. Es decir, que en la brecha de las PCD tendrían protagonismo tanto esas formas de exclusión construidas por la sociedad propias de la discapacidad (un limitado acceso a la educación, a la cultura, al trabajo, precarización económica, etc.) como así también, y al observar el aspecto tecnológico, la escasez y o ausencia de TD desarrolladas bajo criterios de accesibilidad y diseño universal. Asimismo, hay que subrayar que la falta de acceso a las TD, las cuales tienen un papel central en los procesos de producción en el capitalismo cognitivo, se vincularía con las mencionadas situaciones de exclusión, favoreciendo su profundización.

En segundo lugar, es preciso señalar el disminuido número de antecedentes o estadísticas que indagan en la brecha digital de la población general o con discapacidad en el NOA. En el caso de la primera, y desde la última estadística disponible elaborada por el Estado Argentino (2018) se advierten los índices más bajos del país en el acceso y uso de TD (computadora, internet y celular), en comparación a la media nacional y al resto de las regiones. Sin embargo, se advierte como excepción la tasa de acceso a internet en los hogares, la cual sería la más alta en todo el país.

Por su parte, en los antecedentes específicos de la población con discapacidad, los informes elaborados por las ONG que nuclean a las PCD en la Argentina no ofrecen estadísticas específicas sobre la brecha digital. No obstante, afirman que en el caso de los sitios webs del Estado Argentino no se respetan las normas de Accesibilidad Web, lo que limitaría el acceso a los contenidos estatales en internet. Asimismo, otro informe presentado por la UNESCO afirma que la brecha digital de las PCD se encuentra extendida por toda América Latina y debe ser atendida de forma apremiante puesto que limita la inclusión de este grupo social en diversas esferas sociales. En términos estadísticos, esta se manifestaría en la región latinoamericana con una diferencia de 6 a 30 puntos porcentuales en los índices de acceso a las TD, en relación a la población sin discapacidad. Por último, el Estado Argentino expone en otro informe la puesta en marcha de diversas políticas públicas que buscarían atender la problemática, incluyendo algunas en espacios educativos. Pero no 
ofrece estadísticas de diagnóstico, solo una enumeración sucinta de las acciones realizadas. Es por ello que consideramos crucial realizar una indagación más profunda en el campo de las políticas públicas en trabajos posteriores. Esto a los fines de conocer con mayor profundidad cuales fueron las medidas que se tomaron desde el Estado para reducirla.

Por su parte, hemos recorrido las diferentes concepciones en torno a la discapacidad y la importancia del modelo social para su comprensión, lo que nos permite concebir a la misma como una categoría social y política. Con ello podemos argumentar que las causas de la discapacidad no estarían en el cuerpo de las PCD, sino en un amplio universo de barreras que construye la sociedad y que impiden su plena participación. Luego, observamos el camino de este modelo hacia el paradigma de los derechos humanos mediante la Convención, lo que sitúa al acceso a las TD por parte del colectivo como un derecho fundamental para la inclusión social, donde la "Accesibilidad" y el "Diseño universal" se constituyen en criterios fundamentales para su concreción. Asimismo, y en este marco de entendimiento, la educación para las personas con discapacidad se constituye también en un derecho primordial, en la medida en que favorece el acceso a otros derechos como el trabajo, la cultura y la formación ciudadana. No obstante, el mismo no es garantizado plenamente por el Estado Argentino, y la única investigación que analiza el cumplimiento de este derecho en la región del NOA está en proceso.

Otro aspecto relevante en el que profundizamos fue en las potencialidades de las TD para la educación inclusiva. En este sentido, por sus características contribuyen a la accesibilidad en la comunicación y a los artefactos culturales, permiten superar barreras físicas y cognitivas, y con ello, sirven de apoyo a la participación de los estudiantes con discapacidad en los procesos de aprendizaje. No obstante, estas potencialidades se verán limitadas si las mismas no cuentan con los criterios de accesibilidad y diseño universal, y de un enfoque pedagógico que favorezca la inclusión de los estudiantes con discapacidad.

Finalmente, esperamos con este trabajo haber dejado clarificados los cimientos teóricos de esta investigación para cuestionar modelos excluyentes de la discapacidad, que reducen las causas de su existencia a una maldición, enfermedad o tragedia personal vivida o "sufrida" de forma individual, y que niegan sistemáticamente las causas sociales de la misma. Asimismo, haber alejado el canto de sirenas del determinismo tecnológico que, a nivel general, 
conciben a las tecnologías como artefactos neutrales, invisivilizando su dimensión social; y que en la educación, busca persuadirnos de pensar que la sola presencia de toda novedad tecnológica, con entrañas de silicio y rostro luminoso, mejorará la enseñanza y el aprendizaje, olvidando el papel crucial de la reflexión pedagógica. Así, las TD son un recurso valioso para los procesos de educación inclusiva de las PCD, pero serán instrumentos inertes si no se conocen las barreras sociales que limitan su utilización en los entornos educativos de la educación formal, o si esta última no se encuadra en un modelo de educación inclusiva y de derechos humanos, donde todas las personas, por su solo carácter de persona, tienen el derecho a la educación.

\section{Referencias}

Adell Segura, J. y Castañeda Quintero, L. (2010). Los Entornos Personales de Aprendizaje (PLEs): una nueva manera de entender el aprendizaje. En Roig Vila, R. y Fiorucci, M. (Eds.). Claves para la investigación en innovación y calidad educativas. La integración de las Tecnologias de la Información y la Comunicación y la Interculturalidad en las aulas. Alcoy: Marfil - Roma TRE Universita degli studi.

Ainscow, M. y Miles, S. (2008). Por una educación para todos que sea inclusiva: ¿Hacia dónde vamos ahora? Perspectivas, 38 (1), 17-44. Recuperado de: https://sid.usal.es/articulos/discapacidad/14013/8-2-6/por-unaeducacion-para-todos-que-sea-inclusiva-hacia-donde-vamos-ahora.aspx

Banderas Martinez, C. (2014). Los procesos comunicativos en el aula. Una reflexión desde la pragmática. Sincronía, (66), 54-60. Recuperado de: https://www.redalyc.org/pdf/5138/513851572003.pdf

Barrozo, N. (2018). Educación secundaria y Discapacidad: entre la obligatoriedad, igualdad e inclusión. Revista RUEDES, (8), 32-47. Recuperado de: http://revistas.uncu.edu.ar/ojs/index.php/ruedes/article/view/1658

Cabezas, S. (2016). Entornos aumentados de aprendizaje. En XI y XII Jornadas de cooperación educativa con Iberoamérica sobre educación especial e inclusión educativa. París: Unesco. Recuperado de: https://unesdoc.unesco.org/ark:/48223/pf0000246790

Cañón Rodriguez, R., Grande de Prado, M. y Cantón Mayo, I. (2016). Brecha digital: Impacto en el desarrollo social y personal. Tendencias Pedagógicas, (28), 116-132. Recuperado de: https://revistas.uam.es/tendenciaspedagogicas/article/view/4208 
Castells, M. (2009). Comunicación y poder. México: Siglo XXI Editores.

Castorina, J. A. (2016). El significado del marco epistémico en la teoría de las representaciones sociales. En Cultura y Representaciones Sociales, 11 (21), México, Sep.

DOI: http://www.scielo.org.mx/pdf/crs/v11n21/2007-8110-crs-11-21-

\section{9.pdf}

Coll, C. (2009). Aprender y enseñar con las TIC: expectativas, realidad y potencialidades. En Carneiro, R., Toscano J.C. y Díaz T. Los desafíos de las TIC para el cambio educativo. Metas Educativas 2021. España: Fundación Santillana.

Cobeñas, P. (2015). Buenas prácticas inclusivas en la educación de personas con discapacidad en la provincia de Buenos Aires y desafíos pendientes. Buenos Aires: Asociación por los Derechos Civiles.

(2016). Jóvenes mujeres con discapacidad en escuelas públicas de la provincia de Buenos Aires: problematizando los procesos de inclusión y exclusión educativa. Tesis de posgrado. Universidad Nacional de La Plata. Facultad de Humanidades y Ciencias de la Educación. Recuperado de: http:/ / www.memoria.fahce.unlp.edu.ar/tesis/te.1213/te.1213.pdf

Dussel, I. y Quebedo, L. (2010). Aprender y enseñar en la cultura digital. Buenos Aires: Santillana.

Federación Argentina de instituciones de ciegos y ambliopes de Argentina, FAICA; Red por los Derechos de las Personas con discapacidad, REDI; Mesa de Trabajo en Discapacidad y DD.HH. de Cordoba, Observatorio en Salud Mental y DD.HH. de Cordoba (2018). Informe Alterno sobre la Situación de los Derechos Económicos, Sociales y Culturales de las Personas con Discapacidad, para el Comité de los Derechos Económicos, Sociales y Culturales. Cordoba. Recuperado de: http://www.redi.org.ar/Documentos/Informes/InformeAlterno-sobre-la-Situacion-de-los-Derechos-Economicos.pdf

Fernández Díaz, E., Jambrino Maldonado, M. y Iglesias Sanchez, P. (2019). Accesibilidad Web. La nueva era de las WCAG 2.1, la transición a las futuras WCAG 3.0. GECONTEC: Revista Internacional de Gestión del Conocimiento y la Tecnología, 7 (2), 43-65. Recuperado de: https://www.upo.es/revistas/index.php/gecontec/article/view/4069

Ferrante, C. (2014). Usos, posibilidades y dificultades del modelo social de la discapacidad. Revista Inclusiones, 1 (3), 31-55. Recuperado de: https://www.researchgate.net/publication/292145162_Usos_posibilidades _y_dificultades_del_modelo_social_de_la_discapacidad 
(2015). Discapacidad y mendicidad en la era de la Convención: ¿Postal del pasado? Convergencia. Revista de Ciencias Sociales, 22 (68), 151-176. Recuperado de: http://www.scielo.org.mx/scielo.php?script=sci_arttext\&pid=S140514352015000200151

(2017). "Luchamos contra aquellos que nos quieren quitar la dignidad de cualquier manera": una entrevista a Emiliano Naranjo. ONTEAIKEN, Boletin sobre Prácticas y Estudios de Acción Colectiva, (23), 107-117. Recuperado de: http://repositoriocdpd.net:8080/handle/123456789/1808

Ferreira, M., y Diaz Velasquez, E. (2009). Discapacidad, exclusión social y tecnologías de la información. Política y sociedad, 46 (1), 237-253. Recuperado de:

https://revistas.ucm.es/index.php/POSO/article/download/POSO09091 30237A/0/0

Galperín, H. (2017). Sociedad digital: Brechas y retos para la inclusión digital en América Latina $y$ el Caribe. Montevideo: UNESCO. Recuperado de: https://unesdoc.unesco.org/ark:/48223/pf0000262860

García Bilbao, A., y Rodriguez Porrero, C. (2000). Nuevas Tecnologías y personas con discapacidad. Psychosocial Intervention, 9 (3), 283-296. Recuperado de: https://www.redalyc.org/pdf/1798/179818254002.pdf

García Vargas, A., Golovanevsky, L. y Chachagua, M. (2015). Usos y acceso a las TICs en Salta y Jujuy. VIII Seminario Regional (Cono Sur) ALAIC, "Políticas, actores y prácticas de la comunicación: encrucijadas de la investigación en América Latina". 27 y 28 de agosto 2015. Córdoba, Argentina. Recuperado de: http://www.alaic2015.eci.unc.edu.ar/files/ALAIC/EJE6/alaic_-_6_-45_2.pdf

Gómez Navarro, D., Alvarado López, R., Martínez Domínguez M. y Díaz de Leon Castañeda, C. (2018). La brecha digital: una revisión conceptual y aportaciones metodológicas para su estudio en México. Entreciencias: Diálogos en la Sociedad del Conocimiento, 6 (16), 49-64. Recuperado de: http://revistas.unam.mx/index.php/entreciencias/article/view/62611

INADI (2012). Documento Temático, Discapacidad y no discriminación. Buenos Aires: Instituto Nacional Contra la Discriminación, la Xenofobia y el Racismo (INADI). Recuperado de: https://cdn.educ.ar/repositorio/Download/file?file_id=96bf919e-2b72446a-b325-fac6609db74c 
INDEC (2014). Población con dificultad o limitación permanente. Buenos Aires: Instituto Nacional de Estadística y Censo. INDEC. Recuperado de: https://biblioteca.indec.gob.ar/bases/minde/1c2010c.pdf

INDEC (2018). Acceso y uso de tecnologías de la información y la comunicación. EPH Cuarto trimestre de 2018. Informes técnicos, 3 (86). Recuperado https://www.indec.gob.ar/uploads/informesdeprensa/mautic_05_19CF6 C49F37A.pdf

Labrada-Martínez, E. (2011). Apropiación tecnológica en personas con discapacidad visual. Reencuentro, (62), 55-65. Recuperado de: https://www.redalyc.org/pdf/340/34021066007.pdf

Landau, M. (2009). El espacio como construcción semiótica. Análisis de materiales multimedia desde una perspectiva multimodal. En Pérez, S. e Imperatore, A. (comp.) Comunicación y Educación en entornos virtuales de aprendizaje. Bernal: Universidad Nacional de Quilmes.

Landau, M. (2013). Las vicisitudes de los materiales educativos en formato digital. Sesión 2 del módulo Análisis de materiales digitales. En Diploma Superior en Educación y Nuevas Tecnologías. PENT. FLACSO Argentina.

Luque Parra, D. y Rodríguez Infante, G. (2009). Tecnología de la Información y Comunicación aplicada al alumnado con discapacidad: un acercamiento docente. Revista Iberoamericana de Educación, 49 (3). Recuperado de: http://riberdis.cedd.net/handle/11181/4404

Martos, E. y Martos García, A. (2014). Artefactos culturales y alfabetización en la era digital. Teoría Educativa, (26), 119-135. Recuperado de: https://revistas.usal.es/index.php/1130-3743/article/view/11912

Mejía Díaz, B. (2018). Smart Head Band. Revista Logos Ciencia \& Tecnología, 10

Recuperado de: https://revistalogos.policia.edu.co:8443/index.php/rlct/article/view/525

OEA (2016). Informe Nacional de cumplimiento de la Convención Interamericana para la eliminación de todas las formas de Discriminación contra las Personas con Discapacidad (CLADDIS) y del Programa de Acción para el decenio de las Américas por los Derechos y la Dignidad de las personas con Discapacidad (PAD) (341). Organización de los Estados Americanos. Recuperado de: https://www.oas.org/es/sedi/ddse/paginas/documentos/ARGENTINA. pdf 
Olarte Encabo, S. (2017). Brecha digital, pobreza y exclusión social. Temas Laborales, (138), 285-313. Recuperado de: https://dialnet.unirioja.es/servlet/articulo?codigo $=6552396$

Oliver, M. (1998). Una sociología de la discapacidad o una sociología discapacitada. En Barton, L. (Cord). Discapacidad y sociedad. Madrid: Morata.

OMS (2011). Informe Mundial sobre la discapacidad. Malta: Organización Mundial de la Salud (OMS). Recuperado de: https://www.who.int/disabilities/world_report/2011/summary_es.pdf

ONU (2006). Convención sobre los Derechos de las Personas con Discapacidad. Nueva York: Organización de las Naciones Unidas (ONU). Recuperado de: https://www.un.org/esa/socdev/enable/documents/tccconvs.pdf

ONU (2011). Aplicación de la Convención sobre los Derechos de las personas con Discapacidad. Informes iniciales presentados por los Estados parte de conformidad con el Artículo 35 (No 1; p. 106). Comité sobre los Derechos de las Personas con Discapacidad. Recuperado de: https://www.refworld.org/cgi$\mathrm{bin} / \mathrm{texis} / \mathrm{vtx} / \mathrm{rwmain} /$ opendocpdf.pdf? reldoc $=\mathrm{y} \&$ docid $=4$ eef54912

ONU (2017). Informe alternativo. Situación de las Personas con Discapacidad en Argentina 2013-2017. (32). Comité sobre los Derechos de las Personas con Discapacidad. Recuperado de: http://www.redi.org.ar/Documentos/Informes/Informe-alternativoArgentina-2017/Informe-Alternativo-Argentina.pdf

Palacios, A. (2008). El modelo social de discapacidad: origenes, caracterización y plasmación en la Convención Internacional sobre los Derechos de las Personas con Discapacidad. Madrid: Cinda.

(2017). El modelo social de la discapacidad y su concepción como cuestión de Derechos Humanos. Revista Colombiana de Ciencias Sociales, 8 (1), 14-18. Recuperado de: https:/ / ri.conicet.gov.ar/handle/11336/78154 Palacios, A. y Romañach, J. (2006). El modelo de la diversidad. La Bioética y los Derechos Humanos como herramientas para alcanzar la plena dignidad en la diversidad funcional. Madrid: Diversitás Ediciones.

Raja, D. (2016). Bridging the disability divide through digital technologies. Background Paper for the 2016 World Development Report: Digital Dividends. Nueva York, World Bank. Recuperado de: http:/ /pubdocs.worldbank.org/en/123481461249337484/WDR16-BPBridging-the-Disability-Divide-through-Digital-Technology-RAJA.pdf Sánchez Montoya, R. (2016). Comunicación aumentativa y/o alternativa: metodología, computadoras y dispositivos móviles. En XI y XII Jornadas 
de cooperación educativa con Iberoamérica sobre educación especial e inclusión educativa. París: Unesco. Recuperado de: https://unesdoc.unesco.org/ark:/48223/pf0000246790

Silva Sán dez, G. y Rodríguez Miranda, F. (2018). Una mirada hacia las TIC en la educación de las personas con discapacidad y con Trastorno del espectro autista: Análisis temático y bibliográfico. EDMETIC, Revista de Educación Mediática y TIC, 7 (1), 43-65. Recuperado de: https: / / dialnet.unirioja.es/servlet/articulo?codigo $=6382214$

Selwyn, N. (2004). Reconsidering political and popular understandings of the digital divide. New Media and Society, 6 (3), 341-362. Recuperado de: https://journals.sagepub.com/doi/10.1177/1461444804042519

Soto, M. (2017). Una evaluación de accesibilidad web a sitios universitarios. RevCom, (5), 191-205. Recuperado de: https://perio.unlp.edu.ar/ojs/index.php/revcom/article/view/4491

Soto, M., y Lacuadra, C. (2016). La comunicación más allá de la vista. Experiencia de un seminario sobre Accesibilidad Comunicacional. Actas De Periodismo Y Comunicación, 2 (1). Recuperado de: https://perio.unlp.edu.ar/ojs/index.php/actas/article/view/4031

Thomas, H., Juarez, p. Y Picabea, F. (2015). Cuadernillo $N^{\circ} 1$. ¿Qué son las tecnologias para la inclusión social? Colección tecnología y desarrollo. Bernal: Red de tecnologías para la inclusión social y Universidad Nacional de Quilmes. Recuperado de: https://issuu.com/redtisa/docs/cuadernillo_n1_online

Urroz, G. (2015). La accesibilidad como herramienta de inclusión social. En Convención sobre los Derechos de las Personas con Discapacidad: abordajes para la plena inclusión. Buenos Aires: Copidis. Recuperado de: https://www.buenosaires.gob.ar/sites/gcaba/files/compilado_de_autores - $0 . p d f$

Van Dijk, J. (2017). Digital divide: impact of access. En Rössler, P., Hoffner A. y Van Zoonen L. (eds.). The International Encyclopedia of Media Effects (1-11), Chichester, UK: John Wiley y Sons.

Vázquez Cano, E. (2012). Propuesta de un inventario de recursos tecnológicos para el tratamiento del alumnado con discapacidad en el espacio europeo de educación superior. Tendencias Pedagógicas, 20, 71-92. Recuperado de: https://revistas.uam.es/tendenciaspedagogicas/article/view/2015

Victoria Maldonado, J. (2013). El Modelo Social de la Discapacidad: una cuestión de Derechos Humanos. Boletín mexicano de derecho comparado, Nueva 
Serie, $45 \quad$ (138), 1093-1109. Recuperado de: http://revistas.uned.es/index.php/RDUNED/article/viewFile/11716/111 63

Zukerfeld, M. (2008). Capitalismo Cognitivo, trabajo informacional y un poco de música. Nómadas, (28), 52-66. Recuperado de: https://dialnet.unirioja.es/descarga/articulo/5508087.pdf (2012). Capitalismo y conocimiento. Materialismo cognitivo, propiedad intelectual y capitalismo informacional. Volumen I: El Materialismo Cognitivo y la Tipología de los Conocimientos. Tesis doctoral. Facultad Latinoamericana de Ciencias Sociales -FLACSO-. Recuperado de: https://flacso.org.ar/wpcontent/uploads/2013/09/Zukerfeld-Mariano-Abstract-tesis-doctoral.pdf (2015). Las tecnologías en general, las digitales en particular. Vida, milagro y familia de la "Ley de Moore". Hipertextos: Capitalismo, Técnica y Sociedad en debate, 3 (4). 